\title{
Azathioprine-Induced Tubulo-Interstitial Nephritis in Graft Kidney Transplant
}

\author{
Salima Al-Alawi ${ }^{1}$, Issa Al Salmi ${ }^{*}$, Divij K Jha ${ }^{1}$, Naima Al-Alawi ${ }^{1}$ and Suad Hannawi ${ }^{2}$ \\ ${ }^{1}$ The Renal Medicine Department, the Royal Hospital, Muscat, Oman \\ ${ }^{2}$ The Medicine Department, MOHAP, Dubai, UAE
}

\begin{abstract}
Kidney Transplant is the gold standard care for end-stage kidney disease (ESKD). Immunosuppression has a central role to maintain the graft function and its survival. Despite newer agents, still old agents such as azathioprine is still used by many clinicians at various places world-wide. However, hypersensitivity reactions, such as tubulointerstitial nephritis, can occur after starting these medications. There can be many causes of tubulointerstitial nephritis; drugs, infections and autoimmune diseases e.g.: sarcoidosis, systemic lupus erythematous and Sjogren's syndrome.

We report a case of acute interstitial nephritis after introduction of azathioprine in a kidney transplant recipient.

A young female with a living related kidney transplant on triple immunosuppression medication consisting of prednisolone, tacrolimus and mycophenolate mofetil, expressed her desire to conceive eight months after her wedding. Accordingly, mycophenolate mofetil was replaced by azathioprine. In subsequent visits it was observed that her graft kidney function was deteriorating progressively. All possible causes which could contribute to graft function deterioration were evaluated and a graft biopsy was performed. The biopsy showed moderate interstitial inflammatory infiltrate rich in eosinophils with no evidence of cellular or antibody mediated rejection. It was successfully treated by stopping azathioprine and starting high dose oral prednisolone.

Deterioration of kidney function in kidney transplant patients, who are put on azathioprine, should raise the suspicion of tubulointerstitial nephritis as a differential diagnosis.
\end{abstract}

\section{Introduction}

Non communicable disease has reached a staggering magnitude across the globe. In a parallel fashion, the incidence and prevalence of end-stage kidney disease (ESKD) is rising worldwide and the situation even worse in the developing countries [1,2]. Azathioprine (AZA) is a well-known drug that is mostly well-tolerated, but numerous side effects are recognized $[3,4]$. These can be divided into two categories: dose-dependent toxic side effects and rarely, dose-independent hypersensitivity reactions [3].

The time lag to symptoms in hypersensitivity reactions is wide, ranging from 1 week to 16 months after starting therapy, but occurs more frequently in the first 4 weeks $[5,6]$.

Allergic interstitial nephritis (AIN) is the most common form of acute interstitial nephritis [7,8]. It is frequently triggered by introduction of a medication. AIN is usually linked with an acute decrease in kidney function and could lead to permanent damage and results in chronic kidney disease if not managed properly [5,7-9]. The typical clinical features of AIN include but not limited to fever, rash, eosinophilia that are well-described and cessation of the offending drug is the mainstays of management strategy, with inconsistent evidence concerning the benefit of steroid treatment [6,7].

Interstitial nephritis is a common cause of kidney injury. Drugs contribute to about $70-75 \%$ of cases among other causes of interstitial nephritis $[5,8,10,11]$. Kidney biopsy typically showed finding of a significant inflammatory infiltrate of the kidney interstitium that is characteristic of AIN [7].

Here we report on a case of a young lady with graft kidney transplant that started azathioprine treatment prior to conception and developed deterioration of her graft function within a month period. This is followed by mini review of the existing literature.

\section{Case report}

A 33-year-old female, with a history of lupus nephritis and chronic kidney disease stage $\mathrm{V}$ underwent a living related kidney transplantation (donor is her sister) at the Royal Hospital, Muscat, Oman on May 17, 2009. After kidney transplantation, the maintenance immunosuppression medications consisted of prednisolone, tacrolimus and mycophenolate mofetil. She continued to be on the same medications for 10 years. She got married and few months later, expressed the desire to have a child. Consequently, mycophenolate mofetil was replaced by azathioprine in order to reduce her risk of teratogenicity.

A month after starting azathioprine, it was noted that her graft function was deteriorating from a baseline serum creatinine of $100 \mu \mathrm{mol} / \mathrm{l}$, to $184 \mu \mathrm{mol} / \mathrm{l}$, as shown in Table 1 .

Urinalysis did not reveal presence of hematuria or proteinuria and there was no leukocyturia or eosinophiluria. The tacrolimus level was acceptable as her usual level at around $5 \mu \mathrm{g} / \mathrm{l}$.

Polyomavirus and Cytomegalovirus PCR were below detectable levels. A graft kidney biopsy was performed. The biopsy showed a

${ }^{\star}$ Correspondence to: Issa Al Salmi, MD, BA, BAO, Bch, MB (Trinity College), FRCPI, MRCP (UK), FRCP, MIPH, PhD (AUS), FASN (USA), The Royal Hospital, 23 July Street, P O Box 1331, code 111, Muscat, Oman, Tel: 968 92709000; Fax: 968245 99966; ORCID: 0000-0002-3443-5972, Research ID: J-4622-2014; E-mail: isa@ausdoctors.net

Received: July 17, 2020; Accepted: July 24, 2020; Published: July 28, 2020 
Table 1. Timeline of worsening of renal function after introducing azathioprine

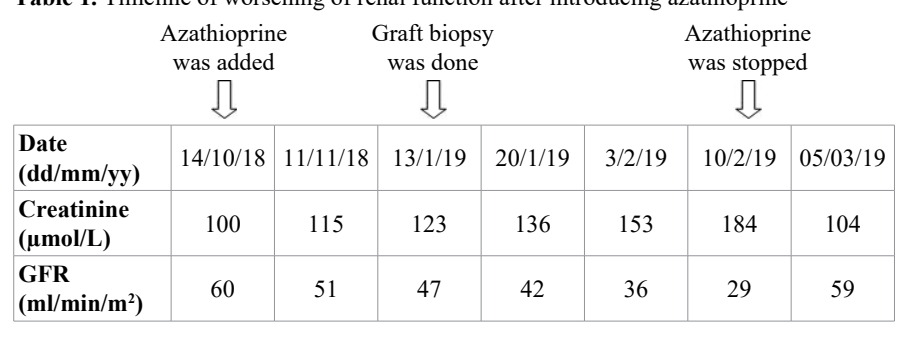

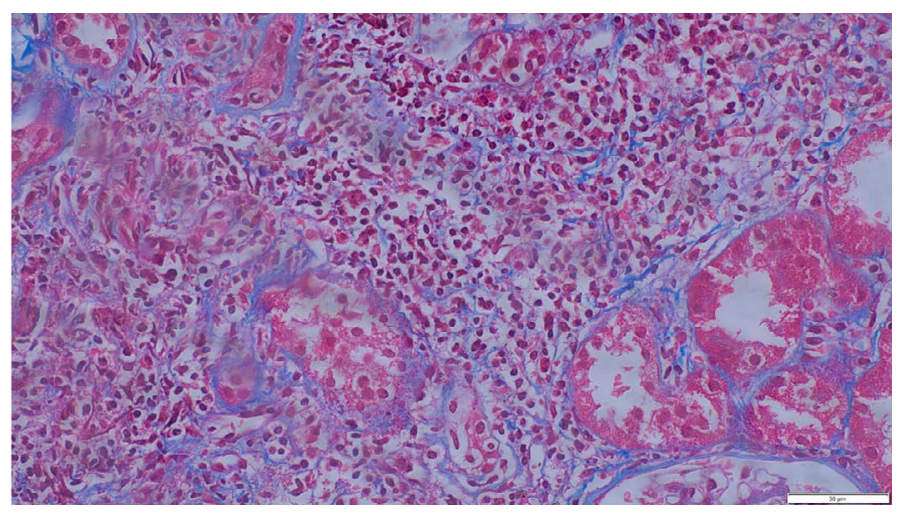

Figure 1. Masson trichrome stain; $x 400$ interstitial inflammation rich in eosinophils

moderate interstitial inflammation rich in eosinophils and there was no evidence of rejection, as shown in Figure 1.

Drug induced interstitial nephritis was suspected and since azathioprine was the only new medication that was started, it was stopped and mycophenolate mofetil was resumed. The dose of prednisolone was increased to $40 \mathrm{mg}$ per day for a week. It was then tapered over a course of three weeks to $5 \mathrm{mg}$. Her serum creatinine level and eGFR improved towards her usual baseline level.

\section{Discussion}

To the best of our knowledge, this is the first report of a kidney transplant recipient in whom graft kidney function deteriorated upon introduction of azathioprine. Kidney biopsy revealed moderate interstitial inflammatory infiltrate rich in eosinophils with no evidence of cellular or antibody mediated rejection. The graft kidney function improved after the cessation of azathioprine and increasing the dose of steroids.

Azathioprine is used as an immunosuppressant medication since 1961 but it is less widely used in organ transplantation and autoimmune rheumatological disorders $[4,8,12]$. It has a list of known side effects namely, gastrointestinal upset, leucopenia, thrombocytopenia, myalgia but interstitial nephritis is not very well known, such that it is not included in the list of medications causing tubulointerstitial nephritis (TIN) [3-5,7].

Interstitial nephritis due to azathioprine has only been confirmed by biopsy in 13 cases [5-8,13,14]: five cases of granulomatosis with polyangiitis; one of anti-neutrophil cytoplasmic antibody (ANCA) associated vasculitides, one of polyarteritis nodosa; two of HenochSchönlein purpura; one of Goodpasture syndrome; one of chronic glomerulonephritis; and two transplant recipients. TIN caused by azathioprine is a rarity with two case reports in anti-neutrophil cytoplasmic antibody [13] and Wegener's granulomatosis [14] and two more in kidney transplant recipients. Renal impairment with biopsy- proven interstitial nephritis is a rare event that has been reported in patients with vasculitides.

Da Rosa reported a 50-year-old Caucasian man with kidney-limited ANCA myeloperoxidase (MPO) vasculitis who presented with general malaise, fever, worsening renal function, and elevated inflammatory markers 2 weeks after the initiation of therapy with oral AZA [7]. Although a disease relapse was suspected, kidney biopsy revealed an eosinophilic infiltrate, suggestive of acute interstitial nephritis. After suspension of AZA, a sustained improvement of kidney function and normalization of inflammatory markers was observed. A diagnosis of allergic interstitial nephritis secondary to AZA was established, corresponding to the first biopsy-proven case described in an ANCA MPO vasculitis patient. Although rare, kidney toxicity of AZA must be present in the clinician's mind, avoiding the straightforward assumption of disease relapse in the case of worsening kidney function [7].

Bir, et al. described a woman with WG who developed rapid progression to sever kidney dysfunction within 10 days of starting azathioprine prescribed as maintenance therapy for vasculitis [5]. Her kidney biopsy showed acute tubulointerstitial nephritis and no active glomerulonephritis. This case illustrates the importance of the history and urine sediment in differentiating drug hypersensitivity from rapidly progressive glomerulonephritis in patients with WG [5]. The kidney biopsy displayed an eosinophilic infiltrate suggestive of acute interstitial nephritis, compatible with hypersensitivity reaction to AZA, in which polymorphonuclear infiltrate constitutes the most reported histological feature but a case of eosinophil-rich infiltrate was also stated [5].

The absence of acute signs of disease activity in the biopsy should be able to weaken the relapse hypothesis, and the time lag to symptoms after drug initiation and the prompt resolution after cessation reinforced the diagnosis of hypersensitivity reaction to AZA [5,6,8,14]. Prognosis is favourable with drug cessation, and re-challenge should be avoided because of the risk of a severe, even life-threatening, acute response within hours $[5,6,8,14]$.

Also, the presence of eosinophilia and eosinophiluria could be supportive of hypersensitivity, but urinary eosinophils are currently considered as a test with poor sensitivity and low positive predictive value, with its absence not excluding the diagnosis [7,8,15-17]. Eosinophilia is present in only $25 \%-50 \%$ of acute interstitial nephritis cases. A list of kidney diseases associated with eosinophilia should be considered in the differential diagnosis including Allergic interstitial nephritis, Transplant rejection, Cholesterol embolic disease, Vasculitis, Diffuse proliferative glomerulonephritis, Thrombotic thrombocytopenic purpura and Renovascular disease [7,8,15-17].

In acute allergic drug-induced interstitial nephritis, the major histologic abnormalities are in the interstitium which is expanded by a number of inflammatory cells with the presence of large numbers of eosinophils, as is seen in this patient $[7,10,15,18,19]$. The true incidence of AZA causing TIN is not very well known. Hence, with any transplant patient who has been started on AZA and develops graft dysfunction, one needs to keep TIN as a differential diagnosis [20-24].

Differentiation from rejection is difficult in most cases and occasionally a re-challenge may be required to see if similar symptoms were developed. There is always a need to check if there was any recent change in the manufacturing of the product. A diagnosis of azathioprine hypersensitivity reaction may be possibly missed. Hence, there is always a need to be aware in the case of a potential confounding variable noticed during the management of transplant and vasculitis patients who were started on azathioprine. 


\section{Funding}

None.

\section{Conflict of interest}

Authors declares no conflict of interest.

\section{References}

1. Al Alawi IH, Al Salmi I, Al Mawali A, Sayer JA (2017) Kidney Disease in Oman: a View of the Current and Future Landscapes. Iran J Kidney Dis 11: 263-270. [Crossref]

2. Al Ismaili F, Al Salmi I, Al Maimani Y, Metry AM, Al Marhoobi H, et al. (2017) Epidemiological Transition of End-Stage Kidney Disease in Oman. Kidney Int Rep 2: 27-35. [Crossref]

3. Ponticelli C, Glassock RJ (2019) Prevention of complications from use of conventional immunosuppressants: a critical review. J Nephrol 32: 851-870. [Crossref]

4. Wang K, Zhang H, Li Y, Wei Q, Li H, et al. (2004) Safety of mycophenolate mofetil versus azathioprine in renal transplantation: a systematic review. Transplant Proc 36: 2068-2070. [Crossref]

5. Bir K, Herzenberg AM, Carette S (2006) Azathioprine induced acute interstitial nephritis as the cause of rapidly progressive renal failure in a patient with Wegener's granulomatosis. J Rheumatol 33: 185-187. [Crossref]

6. Meys E, Devogelaer JP, Geubel A, Rahier J, Nagant de Deuxchaisnes C (1992) Fever, hepatitis and acute interstitial nephritis in a patient with rheumatoid arthritis. Concurrent manifestations of azathioprine hypersensitivity. J Rheumatol 19: 807-809. [Crossref]

7. Da Rosa GP, Marques S, Coelho F, Pereira E, Ferreira E, et al. (2018) Azathioprineinduced interstitial nephritis in an anti-neutrophil cytoplasmic antibody (ANCA) myeloperoxidase (MPO) vasculitis patient. Eur J Rheumatol 5: 135-138. [Crossref]

8. Lyons H, Pinn VW, Cortell S, Cohen JJ, Harrington JT (1973) Allergic interstitial nephritis causing reversible renal failure in four patients with idiopathic nephrotic syndrome. N Engl J Med 288: 124-128. [Crossref]

9. Magalhaes-Costa P, Matos L, Chagas C (2015) Chronic tubulointerstitial nephritis induced by 5 -aminosalicylate in an ulcerative colitis patient: a rare but serious adverse event. BMJ Case Rep 2015. [Crossref]

10. Corica D, Romano C. Renal Involvement in Inflammatory Bowel Diseases. J Crohns Colitis 10: 226-235. [Crossref]
11. Shin JI, Lee JS, Jeong HJ (2006) Azathioprine and tubulointerstitial nephritis in HSP J Rheumatol 33: 2551. [Crossref]

12. Scheitlin W, Brunner F (1967) Follow-up studies of Zurich clinical cases. Z Gesamte Exp Med 143: 352-325. [Crossref]

13. McHenry PM, Allan JG, Rodger RS, Lever RS (1993) Nephrotoxicity due to azathioprine. Br J Dermatol 128: 106. [Crossref]

14. Parnham AP, Dittmer I, Mathieson PW, McIver A, Dudley C (1996) Acute allergic reactions associated with azathioprine. Lancet 348: 542-543. [Crossref]

15. Korsten P, Muller GA (2015) Interstitial nephritis in rheumatic diseases. Z Rheumatol 74: 290-299. [Crossref]

16. Saha MK, Tarek H, Sagar V, Abraham P (2014) Role of tumor necrosis factor inhibitor in granulomatous interstitial nephritis secondary to Crohn's disease. Int Urol Nephrol 46: 229-233. [Crossref]

17. Senel MF, Van Buren CT, Etheridge WB, Barcenas C, Jammal C, et al. (1996) Effects of cyclosporine, azathioprine and prednisone on Kimura's disease and focal segmental glomerulosclerosis in renal transplant patients. Clin Nephrol 45: 18-21. [Crossref]

18. Maroz N, Field H (2015) Necrotizing crescentic glomerulonephritis related to sarcoidosis: a case report. J Med Case Rep 9: 282. [Crossref]

19. Plafkin C, Zhong W, Singh T (2019) ANCA vasculitis presenting with acute interstitia nephritis without glomerular involvement. Clin Nephrol Case Stud 7: 46-50. [Crossref]

20. Aringer M, Houssiau F, Gordon C, Graninger WB, Voll RE, et al. (2009) Adverse events and efficacy of TNF-alpha blockade with infliximab in patients with systemic lupus erythematosus: long-term follow-up of 13 patients. Rheumatology (Oxford) 2009;48(11):1451-4. [Crossref]

21. Das U, Dakshinamurty KV (2013) Safety and efficacy of everolimus in chronic allograft nephropathy. Saudi J Kidney Dis Transpl 24: 910-916. [Crossref]

22. Li C, Li H, Wen YB, Li JN, Lin WF, et al. (2017) Clinicopathological Features of Idiopathic Membranous Nephropathy in 33 Adolescents. Zhongguo Yi Xue Ke Xue Yuan Xue Bao 39: 544-551. [Crossref]

23. Momtaz M, Fayed A, Wadie M, Gamal SM, Ghoniem SA, et al. (2017) Retrospective analysis of nephritis response and renal outcome in a cohort of 928 Egyptian lupus nephritis patients: a university hospital experience. Lupus 26: 1564-1570. [Crossref]

24. Pozdzik AA, Brocheriou I, Demetter P, Matos C, Delhaye M, et al. (2012) Azathioprine as successful maintenance therapy in IgG4-related tubulointerstitial nephritis. Clin Kidney J 5: 225-228. [Crossref]

Copyright: (C2020 Al-Alawi S. This is an open-access article distributed under the terms of the Creative Commons Attribution License, which permits unrestricted use, distribution, and reproduction in any medium, provided the original author and source are credited. 